\title{
A defesa da Baía de Guanabara no início do século XVIII: o episódio da resistência no Morro de São Bento
}

\section{Guanabara Bay's defense in the early 18th century: the resistance episode at Morro de São Bento}

\author{
Miguel Arcanjo Filho \\ Programa de Pós-Graduação em História das Ciências e das Técnicas e \\ Epistemologia (HCTE), Universidade Federal do Rio de Janeiro (UFRJ). \\ arcanjo@hcte.ufrj.br \\ orcid.org/0000-0001-7536-1095 \\ Nadja Paraense dos Santos \\ Programa de Pós-Graduação em História das Ciências e das Técnicas e \\ Epistemologia (HCTE), Universidade Federal do Rio de Janeiro (UFRJ). \\ nadja@iq.ufrj.br \\ orcid.org/0000-0003-2844-0337
}

Resumo. No início do século XVIII, precisamente na manhã do dia 12 de setembro de 1711, o Rio de Janeiro sofreu, o que podemos chamar de forma pouco precisa, sua terceira grande tentativa de invasão por franceses. Esse ataque foi liderado pelo nobre bretão René Du Guay-Trouin que conseguiu romper as defesas da entrada da Baía de Guanabara realizando uma ocupação em solo carioca que durou até o dia 13 de novembro desse mesmo ano. Este trabalho pretende ser uma breve releitura do papel do Mosteiro de São Bento no episódio da invasão perpetrada por Du Guay-Trouin, no sentido de mostrar que o Mosteiro, para além de suas atividades religiosas, desempenhou durante o século XVIII a importante missão de participar da efetiva defesa da cidade do Rio de Janeiro.

Palavras-chave: Invasões francesas. Mosteiro de São Bento. Defesa do Rio de Janeiro.

Abstract. In the beginning of the 18th century, precisely on the morning of September 12, 1711, Rio de Janeiro suffered what we might call, in an imprecise way, its third great attempt of invasion by the French. This attack was led by the noble Briton René Du Guay-Trouin who managed to break through the defenses 
at the entrance of Guanabara Bay by carrying out an occupation on Rio de Janeiro that lasted until November 13 of that same year. This paper intends to briefly reinterpret the role of São Bento Monastery in the episode of the invasion perpetrated by Du Guay-Trouin. Our aim is to show that, in addition to its religious activities, the Monastery took an important part on the effective defense of the city of Rio de Janeiro during the 18th century.

Keywords: French invasions. São Bento Monastery. Defense of Rio de Janeiro.

Recebido: 01/10/2017 Aceito: 27/10/2017 Publicado: 06/11/2017

\section{Introdução}

Rigorosamente o uso do termo invasão não deve ser aplicado, sem alguma reserva, no que diz respeito às três expedições francesas que ocorreram no Rio de Janeiro colonial. A primeira, comandada por Nicolas de Villegagnon (1510-1571), ainda no século XVI, somente poderia ser definida como invasão se naquele momento Portugal já estivesse estabelecido na região da Baía de Guanabara uma colônia com todo o aparato legal, administrativo e militar devidos, caracterizando com isso o efetivo status de território português para a região. O núcleo administrativo de todo o território estava na capitania de São Vicente, numa distribuição de poderes que apenas possuía validação interna, isto é, para os estrangeiros, a região da Baía de Guanabara ainda era terra a ser explorada e os relatos da presença de franceses comerciando com os naturais, sem nenhuma intervenção portuguesa, confirma esse ponto de vista. Quanto às outras duas expedições posteriores, a de 1710 comandada por Jean François Du Clerc (?-1711) e a de 1711 liderada por René Du Guay-Trouin (1673-1736), pode-se também relativizar sua condição de invasão a um território estrangeiro, por motivos bem diversos. Os ataques franceses devem ser analisados do ponto de vista de ações beligerantes entre nações em guerra declarada, uma vez que Portugal, historicamente aliado da Inglaterra, estava em guerra com a França. Não existiu, por parte dos franceses, a intenção de ocupar definitivamente território estrangeiro, mas a de cortar linhas de suprimentos que abasteciam a coroa portuguesa. Somente do ponto de vista dos autóctones tupinambás foram, portanto, verdadeiras invasões.

Dentro desse contexto geopolítico a defesa de toda região, ao longo dos anos, foi evoluindo de ações que garantissem apenas o reconhecimento da territorialidade portuguesa, para uma efetiva incorporação de um território, que no início do século XVIII já fazia parte das bases de sustentação de Portugal. O Rio de Janeiro era uma das mais importantes cidades do império português, pois de seu porto era escoado o ouro das capitanias de Minas Gerais, além de tabaco, açúcar e outros produtos. Portanto, era de se esperar que a preocupação com as defesas da cidade fosse crescendo ao longo do tempo, tanto com respeito às dificuldades impostas em uma possível e previsível penetração inimiga através da Boca da Barra - com o aparelhamento da Fortaleza de 
Santa Cruz da Barra (1612) e do Forte de São João (1618) - quanto com os fortes que defendessem internamente a cidade.

A investida de Du Guay-Trouin contra a cidade, após sua passagem pelas defesas de Santa Cruz e São João, se iniciou já no dia seguinte, 13 de setembro, com a tentativa de tomada da Ilha das Cobras e do Morro dos Beneditinos, de onde veio resistência desproporcional ao que parecia ser uma fácil presa. O relato do tenente francês Louis Chancel de Lagrange descreve a linha de defesa interna da cidade e comprova ser o Mosteiro de São Bento um dos primeiros objetivos estratégicos de Du Guay-Trouin:

O primeiro dos fortes acima assinalados, o de Santiago, situa-se em pequena ponta de terra, proeminente e estendida para o mar; é abobadado e guarnecido com dez bôcas de fogo. O que se lhe segue, o de S. Sebastião ou o Castelo, que cognominamos o Forte Vermelho ou dos Jesuítas, fica no alto de uma colina que domina a cidade, a várzea, o ancoradouro e a barra. É quadrado em sua configuração, possuindo um fôsso e dez peças de poderosos canhões de ferro fundido, de sorte que passa por ser um dos elementos de maior eficácia na defesa local. O terceiro afastado dêste dois tiros de fuzil, sobressai sobre a planície e a barra, sendo denominado de Santa Luzia; oferece o aspecto de um quadrilongo, com doze canhões e uma bateria raza, à flor d'água, de seis peças. Finalmente, o quarto e último, é o de S. Bento, que está em um outeiro e se reduz, apenas, a uma bateria de oito canhões localizados em trincheiras. Defende, não só o próprio mosteiro, mas também, o pôrto e a barra, tendo sido por aí que iniciamos o ataque à cidade propriamente dita (LAGRANGE, 1967, p.57).

O morro dos Beneditinos sempre foi considerado importante pela sua posição estratégica de última unidade de defesa interna da cidade que, pelo relato acima, começava com o forte de São Thiago da Misericórdia (1567). Ainda existem vestígios bem visíveis e de fácil identificação de parte da muralha do Forte de São Thiago da Misericórdia. Na fotografia abaixo (Figura 1) vemos alguns canhões posicionados na muralha remanescente do forte, no local outrora conhecido como Ponta do Calabouço, no Centro da Cidade do Rio de Janeiro, onde atualmente está localizado o Museu Histórico Nacional.

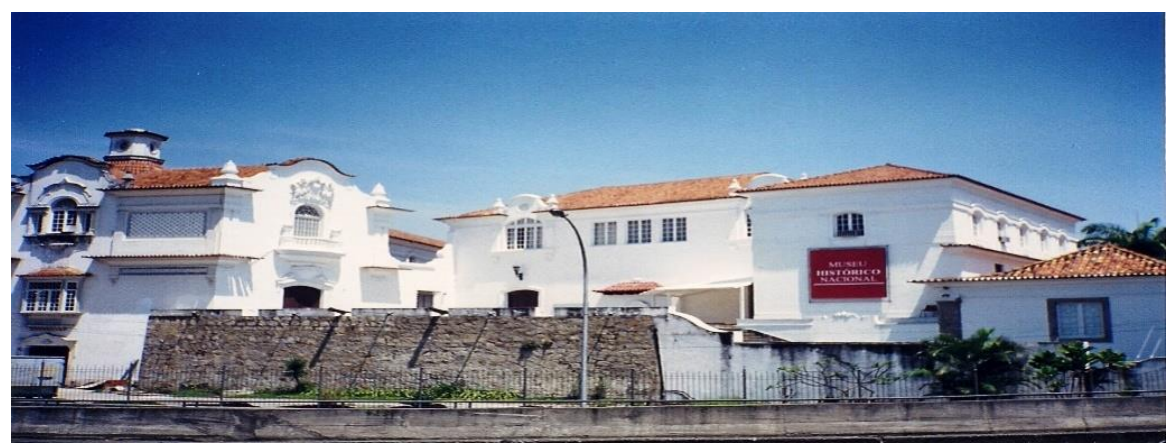

Figura 1.Forte de São Thiago da Misericórdia. Atual Museu Histórico Nacional- Foto de Carlos Luis M.C. da Cruz, 2005. Domínio público. Disponível em: https://commons.wikimedia.org/wiki/File:2005_f_santiago_rj.jpg. Acessado em 28/04/2020. 
Outro fator relevante, com respeito ao Mosteiro de São Bento, apesar do seu acanhado poder defensivo, comparativamente às outras unidades fortificadas, é o fato de a Ilha das Cobras, de propriedade dos Beneditinos até 1696, situar-se bem próxima da encosta do morro do Mosteiro. Essa ilha era um ponto ideal para uma possível base bem abrigada para o escoamento de suprimentos e munições que garantiriam uma possível ocupação da cidade - a escada de pedra que dava acesso ao antigo cais ainda hoje é utilizada pelos funcionários do Mosteiro. O historiador Vivaldo Coaracy relata que a construção do atual Arsenal da Marinha tem início anterior ao ataque de 1711, o que prova a importância estratégica do local onde se encontra o Mosteiro:

Tendo obtido dos frades de S. Bento a cessão de terrenos na base do morro onde se ergue o Mosteiro da ordem, Castro Caldas começou a construir ali um arsenal de guerra e marinha. Esta foi a origem do atual Arsenal de Marinha que, muito ampliado, ainda hoje está situado no mesmo local (COARACY, 1965, p.235)

Os registros dão como sendo o ano de 1696 o início da construção do arsenal anexo ao Mosteiro pelo então governador da cidade Sebastião de Castro Caldas (COARACY, 1965), o mesmo que posteriormente seria muito criticado pela permissão de livre circulação pela cidade do Rio de Janeiro, por mais de um mês, da tripulação francesa da esquadra do almirante Gennes que, em outubro de 1695, passava pela cidade com a missão de estabelecer uma feitoria no Estreito de Magalhães. Esses marinheiros a par de muitas informações sobre a cidade, suas defesas e o calado de seu porto tomaram parte nas expedições de Du Clerc e de Du Guay-Trouin o que favoreceu muito a logística e os planos de ataque do comandante francês em 1711.

\section{A defesa do Morro de São Bento}

O Mosteiro de São Bento foi fundado em 1590. Existem relatos sobre uma contribuição popular que permitiu que os monges beneditinos, mesmo antes da fundação do Mosteiro, comprassem de João Fonseca, em 11 de setembro de 1589, a Ilha das Cobras (ERMAKOFF \& FRAGOSO, 2016). Portanto, a privilegiada situação geográfica do Mosteiro, em conjunto com sua ilha anexa, deve ter sido percebida desde o início de sua fundação, como ponto de defesa estratégico da cidade. Passados exatos 122 anos os atacantes franceses surgem e dominam a ilha, depois de breve peleja com os portugueses que se retiram da mesma após afundarem dois navios em frente ao morro do Mosteiro. Uma vez dominada a Ilha das Cobras os franceses iniciam, no dia 16 de setembro, o ataque ao Mosteiro. Nas palavras do próprio comandante:

No dia 16, devido ao avanço de um de nossos destacamentos, os inimigos armaram uma mina com tamanha precipitação, que não nos causou nenhum mal. No mesmo dia, encarreguei o Sr. De Beauve e o Sr. De Blois da instalação de uma bateria de dez canhões numa península que atacasse pela retaguarda as baterias e parte das trincheiras do morro dos beneditinos (DU GUAY-TROUIN, 2002, p.146). 
O que parecia ser a tomada de uma simples bateria de canhões com algumas trincheiras de defensores se revelou uma luta demorada e com muitos revezes de lado a lado. A principal razão para isso se deve ao fato de ser o oficial Gil Hedoisdu Bocage (avô materno do poeta português)o comandante das forças de defesa no morro dos beneditinos, um francês da Normandia naturalizado português que conhecia diversas técnicas utilizadas pelo inimigo (FRANÇA, 2000). Bocage atuou durante anos como corsário francês com experiência em comando de tropas e, portanto, conhecedor das artimanhas militares e estratégias de combate típicas dos seus antigos compatriotas que naquela altura atacavam a guarnição que ele defendia ao redor do Mosteiro. Abaixo podemos observar (Figura 2) o Mosteiro no alto da Colina e a Ilha das Cobras bem em frente ao mesmo.



Figura 2.Foto de uma ilustração do Mosteiro de São Bento e da Ilha das Cobras. A atual Praça Mauá, situa-se atrás da colina onde está localizada a igreja do mosteiro. - Foto de André Teles. Acervo

FormArte. Disponível em: http://www.formarte.com.br/projetos-finalizados-mosteiro-de-sao-bento-dorio-de-janeiro. Acessado em 28/04/2020.

Um fator adicional para entender como foi difícil a tomada do Mosteiro beneditino é o seu formato de construção. O edifício principal é guarnecido de muralhas que não perdem em nada para uma verdadeira fortaleza militar. $O$ oficial francês Guillaume François de Parscau, integrante das forças de ocupação de Du Guay-Trouin, descreve a construção sem disfarçar sua admiração pela obra realizada pelos portugueses inimigos: 
Quanto ao convento dos beneditinos, não é tão espaçoso quanto o dos Jesuítas, mas sua igreja é maior e mais notável, formando um conjunto nada inferior ao outro. Sobe-se aí por uma bela ladeira, bem mais suave e mais curta que a dos Jesuítas. Do alto, tem-se, igualmente, uma bela vista. A construção, mais regular no todo que a sua congênere, não é menos sólida, pois, apesar do grande número de tiros de canhão disparados em cheio, da Ilha das Cobras - que se encontra, por assim dizer, à queima-roupa - somente a muralha fronteiriça da ilha ficou consideravelmente danificada. E isso não obstante a sua grossura e os blocos de pedra que a atravessam quase que completamente. Foi essa muralha que poupou o resto das edificações de maiores avarias (FRANÇA, 2000, p.129).

É interessante essa descrição quase poética de um indivíduo que naquele momento participava diariamente de sangrentos combates.

A Figura 3 mostra a posição dos três fortins dentro da cidade citados no presente trabalho. Tomando como referência a Rosa dos Ventos da figura, temos a sudeste o Forte de São Thiago da Misericórdia na Ponta do Calabouço. Ao norte encontramos a Ilha das Cobras que em 1713 já possuía uma ponte que a ligava do continente a um pequeno cais no sopé do Morro de São Bento. A noroeste, encontramos precisamente o Mosteiro de São Bento.

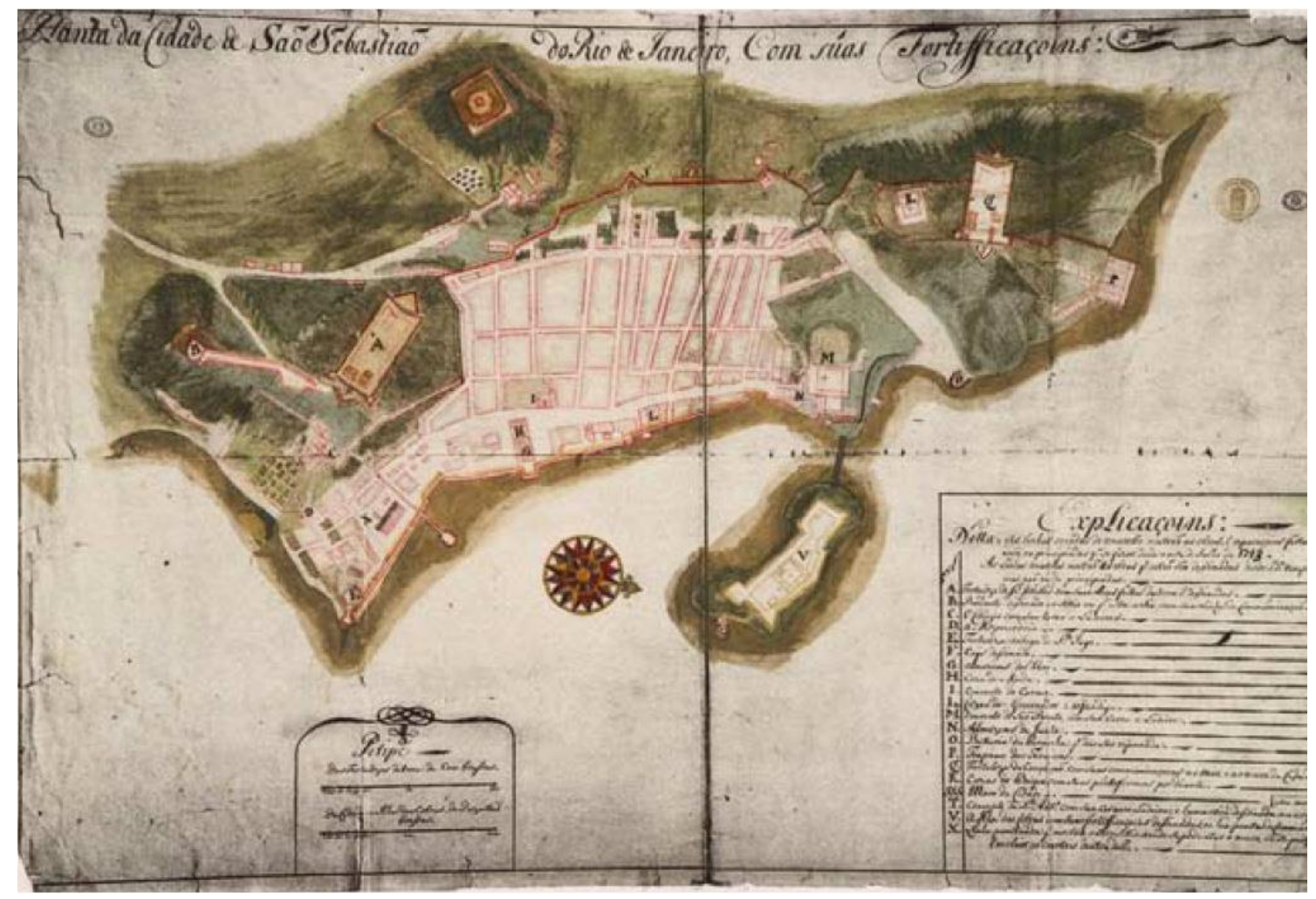

Figura 3. Planta da Cidade de São Sebastião do Rio de Janeiro com suas principais fortificações. Autoria de JeanMassé, 1713. Domínio público. Disponível em: https://commons.wikimedia.org/wiki/File:Rio-Masse1713.jpg. Acessado em 28/04/2020. 
No dia 19 de setembro Du Guay-Trouin resolve intimidar o governador Francisco de Castro Moraes enviando-lhe mensagem que, entre outras exigências, além da capitulação, solicitava a entrega aos franceses dos responsáveis pelo assassinato de Du Clerc, comandante das forças que atacaram o Rio de janeiro no ano anterior. Com a recusa do governador em ceder uma rendição, Du Guay-Trouin resolve intensificar os ataques. No dia 20, dois navios franceses, o Mars e o Brillant, em conjunto com as baterias já instaladas na Ilha das Cobras, somaram fogo contra as trincheiras beneditinas. Já no início da noite se apresentava a formação de uma terrível tempestade que com o clarão de seus relâmpagos, mais tarde, revelaram a movimentação das tropas francesas que se preparavam para o ataque no raiar do dia seguinte. Com essa revelação, as baterias do Mosteiro abriram fogo contra os franceses, que responderam com toda a carga (DU GUAY-TROUIN, 2002). O que deveria ter sido a tradicional trégua noturna se transformou numa batalha ao mesmo tempo sangrenta e pavorosamente barulhenta.

\section{Conclusões}

De posse da Ilha das Cobras e bombardeando constantemente o Mosteiro, os franceses conseguiram, no dia 21, eliminar as baterias de defesa e tomar as trincheiras beneditinas de assalto. Quando rendida, a praça do Mosteiro se transformou em acampamento militar francês. Suas acomodações foram utilizadas como alojamento de oficiais e praças de maior patente, o que trouxe prejuízos vários como depredações e roubos de peças valiosas (CRULS, 1965). Após a tomada do Mosteiro, uma vez que a população da cidade e o restante das tropas portuguesas empreenderam a evacuação do seu núcleo urbano, Du Guay-Trouin inicia as negociações, com os governantes portugueses, dos termos de rendição e as condições para retirar-se da cidade. Portanto, o Mosteiro de São Bento pode ser considerado o último reduto das defesas cariocas no episódio da “invasão" francesa de 1711. Seu lugar de destaque nesse episódio está assegurado para a posteridade e deve ser considerado importante objeto de estudos para futuras explorações históricas e arqueológicas que podem revelar tecnologias utilizadas na defesa da cidade durante o século XVIII como também em séculos anteriores.

\section{Referências}

COARACY, V. O Rio de Janeiro no século 17. Rio de janeiro: Livraria José Olympio Editora, 1965.

CRULS, G. A aparência do Rio de Janeiro,v. 1. Rio de Janeiro: Livraria José Olympio Editora, 1965.

DU GUAY-TROUIN, R. O corsário: uma invasão francesa no Rio de Janeiro. 2.ed. Rio de Janeiro: Bom Texto Editora e Produtora de Arte Ltda, 2002 [1740]. 
ERMAKOFF, G.;FRAGOSO, M. Mosteiro de São Bento do Rio de Janeiro 425 anos. Rio de Janeiro: Edições LumenChristi, 2016.

FERREZ, G. O Rio de Janeiro e a defesa de seu porto. Rio de Janeiro: Serviço de Documentação Geral da Marinha, 1972.

FRANÇA, J.M.C. Outras visões do Rio de Janeiro colonial. Antologia de Textos 1582-1808. Rio de Janeiro: Editora José Olympio Ltda, 2000.

LAGRANGE, L.C de. A tomada do Rio de Janeiro por Duguay-Trouin. Rio de Janeiro: Departamento de Imprensa Nacional, 1967. Disponível em: http://objdigital.bn.br/acervo_digital/div_obrasraras/or383579/or383579.pdf 